\title{
Material World
}

There's no escaping it. We live in a material world and, increasingly, its products are being developed via molecular advances. Nowhere is this more apparent than at the Biomat. net site where some of the descriptions will dazzle visitors. Gander at the single-walled carbon nanotubes that exhibit strong antibacterial activity. Marvel at the magic of self-assembling molecules that build monolayers and make their own surfaces. If your interests extend "outside the envelope" of nonliving materials, you'll probably enjoy reading about the race to make artificial life. With a focus on cutting edge science and technology, Biomat.net serves not only the curious, but also biomaterial professionals, with its news, links to relevant journals, and a section devoted to careers in this emerging field.

www.biomat.net

\section{Tick Tock, Tech Talk}

Updating news articles as reliably as the clock on the wall, The Biotech Weblog is a dependble source for rapidly changing biotech information. If your notion of a blog is a rambling, opinionated diary of an antisocial, 30something still living with mom and dad, then you're in for a pleasant surprise when you stop and smell these roses. Elevating blogging to new heights, The Biotech Weblog excels at providing thought-provoking news items that spotlight biotechnology at its best. Were you aware that bacteria can be used to make nanotubes, or that bees and ants produce silk? How about that rosmarinic acid, a rosemary-derived natural preservative, is a more powerful antioxidant than Vitamin $E$ and is useful for prolonging the shelf-life of prawns? Learn about these unexpected findings and many more at The Biotech Weblog.

\section{www.biotech-weblog.com}

\section{Rats!}

It takes a molecular biologist to love a rat, or so it seems. If importance is measured by priority of determination of genomic sequence, however, these lowly rodents are one of the top species on Earth. An unsavory vector implicated in the transmission of human diseases and a model organism

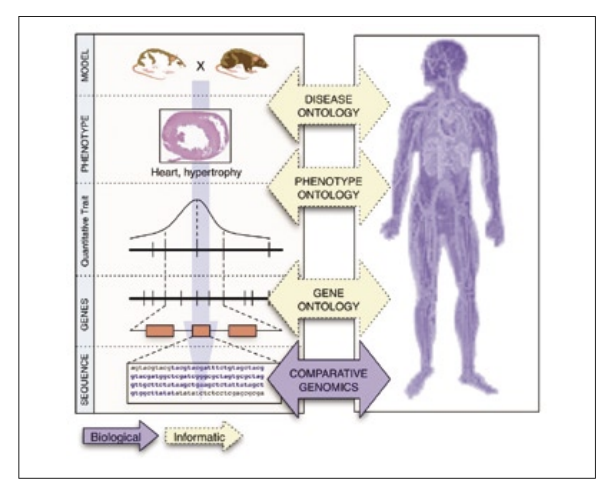

(C) Simon Twigger, Rat Genome Database 2007.

for biology, the rat followed mice and humans in becoming the third mammal to have its genome sequenced. It also has a very useful web site, known as the Rat Genome Database, that delivers volumes of curated research information at the click of a "mouse." Maybe rodents really are taking over the world.

\section{rgd.mcw.edu}

\section{Nano, Nano}

It's one of the buzzwords of the new millennium, but how much do you really know about nanotechnology? That's a question a lot of people are pondering as researchers come to grips with not only exploiting the invisible, almost unimaginable nanoworld, but also educating a wary public about its wonders. Addressing the paucity of awareness about this field is the NISE (Nanoscale Informal
Science Education) Network. NISE focuses its efforts on delivering online information (Nano Knowledge), providing "a place to learn, play, and experiment" (NISENET LAB), and serving up podcast discussions with leaders in the field (SmallTalk). A quick glance at NISE reminds us that not only is it a small world, after all, but there is a lot to learn from it, too.

\section{www.nisenet.org}

\section{Growing Locally}

As globalization continues its march across the planet, concerns about the energetic and environmental costs for the safe movement of food across thousands of miles, from points of production to consumers, grows concomitantly. It is no surprise, therefore, that interest in locally grown, organic food is soaring and it is this important concern that Local Harvest addresses by providing consumers with information about locally produced food for almost any region of the country. On its opening page, one can access local organic farms in a few clicks using an interactive U.S. map. There's also a free newsletter, an active online forum, and options for locating specific foods, farms, or farmer's markets.

\section{www.localharvest.org}

-Kevin Ahern - Please send web site recommendations to ahernk@orst.edu 